\title{
Assessment of Nursing Students' Attitudes Towards Recording and Protecting Patients' Personal Health Data: A Descriptive Study
}

\author{
Sebahat Atalıkoğlu Başkann ${ }^{1^{*}}$ (D), Papatya Karakurt ${ }^{1}$ (D), Necla Kasımoğlu ${ }^{1}$ (D)
}

\begin{abstract}
Introduction. Since health information is considered as sensitive personal data and requires more careful protection, healthcare professionals need to be careful about this issue.

The objective of this research was to determine nursing students' attitudes towards recording and protecting patients' personal health data.

Materials and Methods. The population of this descriptive research consisted of 450 students who studied at the Department of Nursing, Faculty of Health Sciences, Erzincan Binali Yildirim University. Sample selection was not used, and the research was completed with 374 students who were continuing education and who were accepted to participate in the research. Descriptive Information template and Attitude Scale for Recording and Protecting Personal Health Data for nursing students were used as data-collection instruments. The numbers, percentage, mean, standard deviation, non-parametric tests (the Mann-Whitney $U$ test and the Kruskal-Wallis test) were used in data analysis.

Results. Among our research participants, $68.4 \%$ of the students were females; $28.1 \%$ of the students were freshmen; $69 \%$ of the students were graduates of Anatolian high schools. Approximately $72.5 \%$ and $52.9 \%$ of the participants stated that they were aware of the concept of "personal data" and "personal health data", respectively. The mean score of nursing students on the Attitude Scale for Recording and Protecting Personal Health Data was $3.97 \pm 0.71$. The means scores obtained from subscales were as follows: $3.91 \pm 0.72$ for Personal Health Data Information, $4.15 \pm 0.80$ for Legal Information, $4.05 \pm 0.94$ for Legal Data Sharing, $3.90 \pm 0.80$ for Personal Health Data Sharing, and $3.77 \pm 0.33$ for Recording of Personal Health Data, respectively. A statistically significant difference was found between the total scale and subscale scores of the students regarding their academic level.

Conclusions. Students were found to have a positive attitude towards recording and protecting personal data. Increasing the responsibilities and raising awareness of the students for the protection of personal health data during their study is suggested to be important.
\end{abstract}

\section{Keywords}

Health Data; Nursing; Personal Data; Student

${ }^{1}$ Erzincan Binali Yıldırım University Faculty of Health Sciences, Erzincan, Turkey

*Corresponding author: atalikoglu_sebahat@hotmail.com

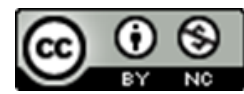

Copyright @Sebahat Atalıkoğlu Başkan, Papatya Karakurt, Necla Kasımoğlu, 2021

\section{Introduction}

Rapid technological developments facilitate the lives of individuals, as well as change the extent of protection of their basic rights and freedoms [1]. Today, due to advances in technology, health data can be stored on digital media and these data can be easily accessed by healthcare providers when needed. By preserving the data obtained at all levels of healthcare services, their quality and efficiency increase; they can be used as an official document in legal proceedings; treatment and care are improved; the data source is available for statistical analysis, enabling the development of public health [2-5]. However, this digital transformation may rise many problems, including violations of personal rights and privacy issues [6]. 
The concept of personal data, as a personal right, cannot be clearly described; however, it is defined as any type of information that relates to or can identify an individual. Information such as individual's name, address, medical history, marital status, ethnic origin, bank account number, social security number, and national identification number is considered as personal data. Personal health data, which are a part of personal data, on the other hand, are considered as sensitive data [7]. The Regulation on Personal Health Data entered into force by the Ministry of Health through publication in the Official Gazette dated June 21, 2019 and numbered 30808. This regulation defines personal health data as "any information related to the physical and mental health of an identified or identifiable natural person including the information related to the provision of healthcare services" [8]. Medical history, examination findings, diagnosis, epicrisis report, health report, any analysis and examination results, medications used, all interventions and care practices recorded during the provision of health service are included in the scope of personal health data [9]. Since health information is considered as sensitive personal data and requires more careful protection, healthcare professionals need to be careful about this issue [10]. Health professionals working in healthcare institutions are responsible for full and proper use of health data of patients who presented to these institutions. The violation of the obligation to protect the confidentiality and sharing patient information with third parties by nurses or other health professionals are against professional rules and ethical guidelines. It is considered as a crime according to the Penal Code and requires criminal liability as well [11].

Since among health professionals, nurses are professionals who work more closely with the individuals receiving healthcare services, nursing staff's awareness about the protection of personal health data and patient's rights should be improved. Determining healthcare students' attitudes towards the protection and privacy of personal health data, increasing their awareness and adding related courses to the healthcare education curriculum can prevent future criminal sanctions [9].

The objective of this research was to determine nursing students' attitudes towards recording and protecting personal health data.

\section{Materials and Methods}

\section{Study Design}

This study is a type of descriptive research, carried out at the Department of Nursing, Faculty of Health Sciences, Erzincan Binali Yildirim University in February of 2018-2019 academic year. The population of the study consisted of 450 students who studied at the aforementioned faculty. Sample selection was not used in the research, and the research was completed with 374 students who were continuing education and who were accepted to participate in the research. Students who did not continue their education at the time of data collection and refused to participate in the study were not included in the study.

\section{Data Collection}

The authors drew a plan with the faculty members and ensured that the data-collection instruments were distributed and completed at a convenient time for students. Socio-demographic characteristics, Descriptive Information template and Attitude Scale for Recording and Protecting Personal Health Data for nursing students were used as data-collection instruments. The data collection process took on average 10-15 minutes for each student.

\section{Descriptive Information Template}

The information form prepared by the researchers contained a total of 6 questions about the students' age, gender, class, high school they graduated from, personal data and personal health data.

\section{Attitude Scale for Recording and Protecting Personal Health Data}

The development of this scale, its validity and reliability analysis were performed by Bezirgan Gözmener et al [9]. This 5point Likert-type scale consists of 31 items and includes 5 subscales. For scale score calculation, the total score is obtained, and the raw score is divided by the number of scale items and thus, the scale score is calculated. For subscale score calculation, following the collection of subscale scores, it is divided by the number of the subscale items and the score obtained is evaluated between 1-5. The cut-off point of the scale was determined as 3. Students' attitudes that scored $<3$ on the scale were evaluated as negative, and students' attitudes that scored $\geq 3$ were accepted as positive. A negative attitude means that students' awareness of recording and protecting personal health data is low, while a positive attitude indicates that students' awareness of recording and protecting personal health data is high. The calculation and evaluation method used for the whole scale was applied to the calculations for all subscales of the scale as well. The Cronbach's alpha coefficient for the whole scale was found to be $\alpha=0.94$. In this study, the Cronbach's alpha reliability coefficient was calculated as $\alpha=0.88$.

\section{Data Analysis}

The data were analyzed by using SPSS statistical software (version 23.0; SPSS Inc, Chicago, IL). The numbers, percentage, mean, standard deviation in descriptive statistics, nonparametric tests (the Mann-Whitney U test, the Kruskal-Wallis test and the Tamhane's T2 test) were used in the analysis of data that did not show normal distribution. A p-value less than 0.05 was considered statistically significant.

\section{Results}

According to Table 1, 67.4\% of the students were at the age of $17-21$ years; $68.4 \%$ of students were females; $28.1 \%$ of the students were freshmen; $69 \%$ of the students were graduates of Anatolian high schools. Approximately $72.5 \%$ and $52.9 \%$ of 
the participants stated that they were aware of the concept of "personal data" and "personal health data", respectively.

Table 1. Distribution of descriptive characteristics among students $(n=374)$.

\begin{tabular}{lcc}
\hline Descriptive Characteristics & $\mathrm{n}$ & $\%$ \\
\hline Gender & & \\
\hline Male & 118 & 31.6 \\
Female & 256 & 68.4 \\
\hline Age & & \\
\hline $17-21$ & 252 & 67.4 \\
$22-25$ & 118 & 31.6 \\
$26-29$ & 4 & 1.0 \\
\hline Academic Level & & \\
\hline Freshman & 105 & 28.1 \\
Sophomore & 104 & 27.8 \\
Junior & 75 & 20.1 \\
Senior & 90 & 24.0 \\
\hline High School Graduate & & \\
\hline Regular high school & 68 & 18.2 \\
Anatolian high school & 258 & 69.0 \\
Vocational health school & 24 & 6.4 \\
Science high school & 6 & 1.6 \\
Other (technical high school, etc.) & 18 & 4.8 \\
\hline Personal Data Awareness Status & & \\
\hline Yes & 271 & 72.5 \\
No & 103 & 27.5 \\
\hline Personal Health Data Awareness Status & \\
\hline Yes & 198 & 52.9 \\
No & 176 & 47.1 \\
\hline
\end{tabular}

The mean score of nursing students on the Attitude Scale for Recording and Protecting Personal Health Data was $3.97 \pm 0.71$. The means scores obtained from subscales were as follows: $3.91 \pm 0.72$ for Personal Health Data Information, $4.15 \pm 0.80$ for Legal Information, $4.05 \pm 0.94$ for Legal Data Sharing, $3.90 \pm 0.80$ for Personal Health Data Sharing, and $3.77 \pm 0.33$ for Recording of Personal Health Data, respectively. Since the cut-off point of the scale was accepted as 3 , students were observed to have a positive attitude towards recording and protecting personal data (Table 2 ).

A significant difference was determined in the mean scores of the Legal Information subscale regarding the participants' gender. The difference between the total scores of the scale and other subscales was determined to be insignificant (Table 3).

According to age variable, a significant difference was determined between the total scores of the Attitude Scale for Recording and Protecting Personal Health Data and the mean scores of the following subscales: Personal Health Data Information, Legal Data Sharing, Recording of Personal Health Data; the difference between mean scores of Legal Information and Personal Health Data Sharing subscales was found to be insignificant (Table 3).
Table 2. Distribution of mean scores in the Attitude Scale for Recording and Protecting Personal Health Data.

\begin{tabular}{lccccc}
\hline Scale and Subscales & $\mathrm{n}$ & Min. & Max. & $\mathrm{X}$ & $\mathrm{SD}$ \\
\hline Personal Health & 374 & 1.00 & 5.00 & 3.91 & 0.72 \\
Data Information & & & & & \\
Legal Information & 374 & 1.00 & 5.00 & 4.15 & 0.80 \\
Legal Data Sharing & 374 & 1.00 & 5.00 & 4.05 & 0.94 \\
$\begin{array}{l}\text { Personal Health } \\
\text { Data Sharing }\end{array}$ & 374 & 1.00 & 5.00 & 3.90 & 0.80 \\
$\begin{array}{l}\text { Recording of Per- } \\
\text { sonal Health Data }\end{array}$ & 374 & 1.00 & 5.00 & 3.77 & 0.33 \\
\hline $\begin{array}{l}\text { Total scores of } \\
\text { nursing students on } \\
\text { the Attitude Scale } \\
\text { for Recording and }\end{array}$ & 374 & 1.00 & 5.00 & 3.97 & 0.71 \\
$\begin{array}{l}\text { Protecting Personal } \\
\text { Health Data }\end{array}$ & & & & & \\
\hline
\end{tabular}

A significant difference was determined between the total scores of the Attitude Scale for Recording and Protecting Personal Health Data and the mean scores of subscales according to the academic level of students participating in the research. The mean scores of junior and senior students were higher than those in freshmen and sophomores (Table 3).

In terms of high school graduate variable, a significant difference was observed between the mean scores of Recording of Personal Health Data subscale; the difference between the total scores of the Attitude Scale for Recording and Protecting Personal Health Data and the mean scores of other subscales was insignificant (Table 3).

With regard to the Personal Data and Personal Health Data Awareness Status, a significant difference was found between the total score of the Attitude Scale for Recording and Protecting Personal Health Data and the mean scores of the following subscales: Personal Health Data Information, Legal Information and Recording of Personal Health Data; on the other hand, the difference between the mean scores of Legal Data Sharing and Personal Health Data Sharing subscales was found to be insignificant (Table 3).

\section{Discussion}

One of the patient's rights in the scope of the right to privacy is to perform all evaluations regarding the patient's health status confidentially [12]. Sharing patient-related information for training healthcare worker candidates is expected to increase in the coming years. Sharing patient information with healthcare professionals, students and other parties may conflict with the regulations regarding the protection of patient's privacy [13]. Recently, many contracts have emphasized the protection of personal data to ensure privacy. Protecting personal health information, one of the areas where confidence is fundamental, is important in terms of protecting the patient's rights in healthcare institutions [10]. 
Table 3. Comparison of students' descriptive characteristics and mean scores on the Attitude Scale for Recording and Protecting Personal Health Data $(n=374)$.

\begin{tabular}{|c|c|c|c|c|c|c|}
\hline $\begin{array}{l}\text { Descriptive } \\
\text { Characteristics }\end{array}$ & $\begin{array}{l}\text { Personal } \\
\text { Health Data } \\
\text { Information }\end{array}$ & $\begin{array}{c}\text { Legal } \\
\text { Information }\end{array}$ & $\begin{array}{l}\text { Legal Data } \\
\text { Sharing }\end{array}$ & $\begin{array}{l}\text { Personal } \\
\text { Health Data } \\
\text { Sharing }\end{array}$ & $\begin{array}{l}\text { Recording of } \\
\text { Personal } \\
\text { Health Data }\end{array}$ & $\begin{array}{c}\text { Attitude } \\
\text { Scale for } \\
\text { Recording } \\
\text { and } \\
\text { Protecting } \\
\text { Personal } \\
\text { Health Data }\end{array}$ \\
\hline & $\mathrm{X} \pm \mathrm{SD}$ & $\mathrm{X} \pm \mathrm{SD}$ & $\mathrm{X} \pm \mathrm{SD}$ & $\mathrm{X} \pm \mathrm{SD}$ & $\mathrm{X} \pm \mathrm{SD}$ & $\mathrm{X} \pm \mathrm{SD}$ \\
\hline \multicolumn{7}{|l|}{ Gender } \\
\hline Female & $3.94 \pm 0.68$ & $4.23 \pm 0.72$ & $4.09 \pm 0.86$ & $3.90 \pm 0.76$ & $3.80 \pm 0.77$ & $4.01 \pm 0.65$ \\
\hline Male & $3.84 \pm 0.80$ & $3.99 \pm 0.93$ & $3.97 \pm 1.08$ & $3.90 \pm 0.88$ & $3.69 \pm 0.94$ & $3.89 \pm 0.82$ \\
\hline $\mathbf{U}$ & 14386 & 13150 & 15059.5 & 14292 & 14085.5 & 14416 \\
\hline $\mathbf{p}$ & 0.459 & 0.043 & 0.963 & 0.4 & 0.29 & 0.479 \\
\hline \multicolumn{7}{|l|}{ Age } \\
\hline $17-21$ & $3.83 \pm 0.73$ & $4.11 \pm 0.79$ & $3.97 \pm 0.98$ & $3.85 \pm 0.83$ & $3.71 \pm 0.83$ & $3.91 \pm 0.71$ \\
\hline $22-25$ & $4.05 \pm 0.69$ & $4.24 \pm 0.82$ & $4.22 \pm 0.82$ & $4.01 \pm 0.75$ & $3.88 \pm 0.82$ & $4.10 \pm 0.68$ \\
\hline $26-29$ & $4.17 \pm 0.41$ & $4.18 \pm 0.89$ & $4.20 \pm 0.58$ & $3.75 \pm 0.46$ & $4.00 \pm 0.82$ & $4.10 \pm 0.52$ \\
\hline KW & 11.185 & 5.222 & 6.469 & 3.935 & 6.266 & 12.045 \\
\hline p & 0.004 & 0.073 & 0.039 & 0.14 & 0.044 & 0.002 \\
\hline \multicolumn{7}{|l|}{ Academic Level } \\
\hline Freshman & $3.74 \pm 0.77$ & $3.98 \pm 0.83$ & $3.77 \pm 1.05$ & $3.74 \pm 0.90$ & $3.64 \pm 0.83$ & $3.79 \pm 0.74$ \\
\hline Sophomore & $3.74 \pm 0.76$ & $4.02 \pm 0.88$ & $3.91 \pm 0.98$ & $3.84 \pm 0.82$ & $3.61 \pm 0.90$ & $3.83 \pm 0.77$ \\
\hline Junior & $4.11 \pm 0.70$ & $4.37 \pm 0.77$ & $4.33 \pm 0.80$ & $4.00 \pm 0.79$ & $3.99 \pm 0.86$ & $4.18 \pm 0.67$ \\
\hline Senior & $4.12 \pm 0.53$ & $4.32 \pm 0.59$ & $4.30 \pm 0.70$ & $4.07 \pm 0.60$ & $3.91 \pm 0.64$ & $4.17 \pm 0.50$ \\
\hline KW & 28.676 & 21.359 & 27.277 & 8.211 & 15.435 & 31.933 \\
\hline p & $\mathbf{0 . 0 0 0}$ & 0.000 & 0.000 & 0.042 & 0.001 & $\mathbf{0 . 0 0 0}$ \\
\hline \multicolumn{7}{|l|}{ High School Graduate } \\
\hline Regular high school & $3.85 \pm 0.75$ & $4.07 \pm 0.83$ & $3.99 \pm 0.88$ & $3.82 \pm 0.90$ & $3.77 \pm 0.85$ & $3.91 \pm 0.73$ \\
\hline Anatolian high school & $3.92 \pm 0.71$ & $4.17 \pm 0.79$ & $4.08 \pm 0.93$ & $3.93 \pm 0.75$ & $3.72 \pm 0.81$ & $3.99 \pm 0.69$ \\
\hline Vocational health school & $4.13 \pm 0.65$ & $4.27 \pm 0.76$ & $4.01 \pm 1.07$ & $4.05 \pm 0.89$ & $4.18 \pm 0.57$ & $4.13 \pm 0.66$ \\
\hline Science high school & $3.60 \pm 0.64$ & $3.93 \pm 0.82$ & $3.70 \pm 1.56$ & $3.38 \pm 0.82$ & $3.22 \pm 1.24$ & $3.62 \pm 0.73$ \\
\hline $\begin{array}{l}\text { Other (technical high } \\
\text { school, etc.) }\end{array}$ & $3.73 \pm 0.84$ & $4.07 \pm 0.92$ & $4.00 \pm 0.88$ & $3.74 \pm 1.01$ & $4.00 \pm 0.97$ & $3.88 \pm 0.81$ \\
\hline KW & 6.284 & 2.909 & 2.177 & 4.89 & 12.784 & 3.952 \\
\hline $\mathbf{p}$ & 0.179 & 0.573 & 0.703 & 0.299 & 0.012 & 0.413 \\
\hline \multicolumn{7}{|c|}{ Personal Data Awareness Status } \\
\hline Yes & $3.93 \pm 0.76$ & $4.19 \pm 0.84$ & $4.06 \pm 0.96$ & $3.93 \pm 0.82$ & $3.81 \pm 0.86$ & $3.10 \pm 0.74$ \\
\hline No & $3.83 \pm 0.61$ & $4.06 \pm 0.67$ & $4.01 \pm 0.86$ & $3.84 \pm 0.74$ & $3.66 \pm 0.73$ & $3.89 \pm 0.60$ \\
\hline $\mathbf{U}$ & 11953.5 & 11038.5 & 12576 & 12198.5 & 12013.5 & 11414 \\
\hline $\mathbf{p}$ & $\mathbf{0 . 0 3 2}$ & 0.002 & 0.137 & 0.058 & 0.036 & 0.006 \\
\hline \multicolumn{7}{|c|}{ Personal Health Data Awareness Status } \\
\hline Yes & $3.95 \pm 0.75$ & $4.22 \pm 0.85$ & $4.07 \pm 1.01$ & $3.93 \pm 0.81$ & $3.83 \pm 0.88$ & $4.02 \pm 0.74$ \\
\hline No & $3.85 \pm 0.68$ & $4.07 \pm 0.74$ & $4.03 \pm 0.85$ & $3.86 \pm 0.79$ & $3.69 \pm 0.76$ & $3.92 \pm 0.66$ \\
\hline $\mathbf{U}$ & 15296.5 & 13886 & 15682 & 16256 & 15261 & 14845 \\
\hline $\mathbf{p}$ & 0.041 & 0.001 & 0.093 & 0.26 & 0.036 & 0.013 \\
\hline
\end{tabular}

Notes: * U: Mann-Whitney U-test, KW: Kruskal-Wallis, $\mathrm{p}<0.05$

The results of our study revealed that the mean scores of nursing students on the Attitude Scale for Recording and Protecting Personal Health Data was $3.97 \pm 0.71$ and they had a positive attitude towards recording and protecting personal data. In a study conducted by Tural Büyük et al., nursing students' attitudes towards recording and protecting patients' personal health data were high [14]. Another study has suggested that most of the students were ready to take ethical 
responsibility for protection of patient's privacy and confidentiality [15]. According to Vaismoradi et al., students emphasized the importance of respecting patients' privacy and ensuring confidentiality of patients' medical records, in terms of patient psychology [16]. In a study conducted by Öztürk et al., the majority of nurses have been found to show respect for personal privacy [17]. A study carried out by Soysal et al. has indicated that students' attitudes towards the patients' rights should be improved [18]. It is suggested that receiving education about the patient's rights and ethical situations during student education and observing different practices related to the patients' rights during their clinical practice may be effective in further results.

According to the results obtained, there was no statistically significant difference between the total scores of the Attitude Scale for Recording and Protecting Personal Health Data between the study participants based on the gender variable. In a study conducted, there was found a statistically significant relationship between students' gender, the Attitude Scale for Recording and Protecting Personal Health Data and all its subdimensions [14]. Similar to this result, another study has revealed that there was no significant difference between gender and privacy, as shown in one of the subscales of the privacy scale $[19,20]$. Furthermore, a previous study, where no significant difference has been found between healthcare professionals' gender and their information level on the patient's rights supported current research findings [21]. Since there was no gender difference regarding the patients' rights and privacy of personal data, this finding is considered as the desired result. However, in the study, the gender was found to affect the legal knowledge subdimension and female participants had a more positive attitude towards recording and protecting personal data. The introduction of many policies, strategies and practices for the empowerment and development of women in our country is believed to be effective in this result.

In terms of the participants' age, a significant difference was observed between the total mean scores of the Attitude Scale for Recording and Protecting Personal Health Data. In line with these findings, other studies have found that with age and, correlatively, with increasing the healthcare professionals' experience, their attitudes towards the protection of personal privacy and personal information increased positively [19-23]. Health care professional candidates are considered to become personally mature with age, and their knowledge level improves by the addition of relevant courses to their curriculum, and as a result of these factors, their attitudes towards confidentiality of personal information may change positively

There was a significant difference between the total mean score of the Attitude Scale for Recording and Protecting Personal Health Data regarding the students' academic level. The mean scores of junior and senior students were found to be higher than those in freshmen and sophomores. According to the study with similar research findings, that there was a statistically significant relationship between the students' academic level and the sub-dimensions of the Attitude Scale for Recording and Protecting Personal Health Data - Personal Health Data Information, Legal Information, and Legal Data Sharing; junior and senior students had higher average scores than freshmen and sophomores [14]. The factors considered effective in these results are that junior and senior students have more clinical practices than freshmen and sophomores, and they have taken more courses on the patients' rights and privacy.

According to the Personal Data and Personal Health Data Awareness Status of the students who participated in this research, a statistically significant difference was found between the total mean scores of the Attitude Scale for Recording and Protecting Personal Health Data. The study has found that the total average attitude in students who had heard the phrase "personal health data" before was higher than that in students who did not, and this average score among students provided a statistically significant difference [24]. Awareness of the importance of protecting students' personal data during their study and the condition of their prior knowledge of personal data and personal health data are considered as effective in enhancing students' knowledge, awareness, and attitudes regarding recording and protecting personal health data.

\section{Conclusions}

According to the results of this study which investigated students' attitudes towards recording and protecting patients' personal health data, students were found to have a positive attitude towards recording and protecting personal data. The students' age, academic level, and prior awareness of personal data and personal health data were found to be effective factors influencing their attitudes towards recording and protecting personal data. More comprehensive inclusion of patients' rights in the curriculum of nursing students as potential advocates of patients, creation of discussion environment, and additional research for recording and protecting personal health data in other programs providing health-related education are recommended.

\section{Ethical Principles for the Research and Informed Consent}

Following the research planning process, the approval (dated February 07, 2019 and numbered 02) was obtained from the Human Research Ethics Committee of the university where the research was conducted; a written permission was obtained from the faculty where the research was carried out; permission from the author, who made the validity and reliability of the scale used in the research, was obtained via e-mail. During data collection, the principle of informed consent, the principle of respect for autonomy and the protection of privacy and confidentiality were fulfilled and the study was carried out in accordance with the Declaration of Helsinki. 


\section{Conflict of Interest}

The authors declare that they have no conflict of interests.

\section{Financial Disclosure}

The authors received no financial support for the research, authorship, and/or publication of this article.

\section{Acknowledgements}

The authors acknowledge the contributions of all patients who took part in the study and thank the clerical staff of the clinic where these data were gathered.

\section{References}

[1] Sözüer E. Right to be forgotten, an investigation in law from a human rights perspective. İstanbul: Twelve-sheet Publishing; c2017.

[2] Endsley S, Kibbe DC, Linares A, Colorafi K. An introduction to personal health records. Fam Pract Manag. 2006;13(5):57-62.

[3] Tengilimoğlu D, Oğuz I, Akbolat M. Health business management. Istanbul: Nobel Academic Publishing; c2017.

[4] Yuan B, Li J. The policy effect of the general data protection regulation (GDPR) on the digital public health sector in the european union: an empirical investigation. International Journal of Environmental Research and Public Health. 2019;16(6):1070. Available from: https://doi.org/10.3390/ijerph16061070

[5] Kişisel Sağlık Verileri Çalışma Grubu. Personal data collection, protection and evaluation in health services. 2021. Available from: http://www.kisiselsaglikverileri.org/32saglik-hizmetlerinde-kisisel-veri-toplanmasi-korunmasive-degerlendirilmesi.html

[6] Yüksel G. Legal protection of personal health data. Heal Care Acad J. 2018;6(1):1-10.

[7] Dülger MV. Protection of personal data and patient privacy in health law. Istanbul Medipol Univ Fac Law J. 2015;1(2):43-80.

[8] Sağlık Bakanlığından. Regulation on personal health data. 2019. Available from: https://www.resmigazete.gov.tr/eskiler/2019/06/201906213.htm

[9] Bezirgan Gözmener S, Şenol S, Seren İntepeler Ş. Validity and reliability study of the record and protection of personal health data for nursing students attitude scale. Dokuz Eylül Univ Fac Nurs Electron J. 2019;12(1):21-30.
[10] Izgi MC. The concept of privacy in the context of personal health data. Turkish Journal of Bioethics. 2014;1(1):25-37. Available from: https://doi.org/10.5505/tjob.2014.65375

[11] Aydin N. The criminality of giving and confiscating data in medical criminal law. J Fac Law. 2013;21(2).

[12] Aydin N. Legal aspects of patient rights and protection ways. Dumlupınar Univ J Soc Sci. 2008;22.

[13] Leijssen LGJ, Linthorst GE, Geukers VG et al. The 'interesting case' and patient privacy: handling patient data in medical education. Ned Tijdschr Geneeskd. 2015;159:A9458.

[14] Tural Büyük E, Ünaldı Baydın N. Association between ethical sensitivity and attitudes towards recording and protecting personal data in nursing students. Turkish Journal of Bioethics. 2020;7(4):198-210. Available from: https://doi.org/10.5505/tjob.2020.93685

[15] Aydin Er R, Ersoy N, Celik S. The nursing students' views about the patient's rights at the west black sea universities in Turkey. Nursing and Midwifery Studies. 2014;3(4). Available from: https://doi.org/10.17795/nmsjournal19136

[16] Vaismoradi M, Salsali M, Marck P. Patient safety: nursing students' perspectives and the role of nursing education to provide safe care. International Nursing Review. 2011;58(4):434-442. Available from: https://doi.org/10.1111/j.1466-7657.2011.00882.x

[17] Öztürk H, Özçelik S, Bahçecik N. Taking care of patient privacy in nursing practices. Ege Univ J Fac Nurs. 2014;30(3):19-31.

[18] Soysal A, Kuşcu FN. Patient rights: an application on university students. Gümüşhane Univ J Heal Sci. 2018;7(1):101-110.

[19] Varol E. Nurses' attitudes towards privacy and effects of care practices on patient privacy. Balıkesir: Balıkesir University Institute of Health Sciences; 2018.

[20] Çolak Z. Evaluation of behaviors of nurses and midwives working in obstetrics departments towards patient privacy; Example of Trabzon province. Trabzon: Karadeniz Teknik University Institute of Health Sciences; 2019.

[21] Yüce I. Measuring knowledge and attitudes of private hospital employees towards patient rights. Istanbul: Biruni University, Institute of Health Sciences; 2018.

[22] Değirmen N, Şaylıgil Ö. Body privacy in gynecology obstetrics. Acta Bioethica. 2020;26(2):225-235.

[23] Candan M, Bilgili N. Evaluation of the views of nurses and midwives regarding patient privacy. Gazi J Heal Sci. 2018;3(3):34-43. 
Assessment of Nursing Students' Attitudes Towards Recording and Protecting Patients' Personal Health Data: A

Descriptive Study - 7/7

[24] Maraş G, Ceyhan Ö. Nursing students' attitudes regarding registration and protection of personal health data. J Inonu Univ Heal. 2021;9(2):498-509. Available from: https://doi.org/10.33715/inonusaglik.851192
Received: 2021-05-21

Revised: 2021-07-03

Accepted: 2021-07-09 